\title{
Experimental Analysis of Concrete Strength at High Temperatures and after Cooling
}

\author{
E. Klingsch, A. Frangi, M. Fontana \\ In recent years, the cement industry has been criticized for emitting large amounts of carbon dioxide; hence it is developing environ- \\ ment-friendly cement, e.g., blended, supersulfated slag cement (SSC). This paper presents an experimental analysis of the compressive \\ strength development of concrete made from blended cement in comparison to ordinary cement at high temperature. Three different types of \\ cement were used during these tests, an ordinary portland cement (CEM I), a portland limestone cement (CEM II-A-LL) and a new, \\ supersulfated slag cement (SSC). The compressive strength development for a full thermal cycle, including cooling down phase, was investi- \\ gated on concrete cylinders. It is shown that the SSC concrete specimens perform similar to ordinary cement specimens.
}

Keywords: fire; concrete; blended cement; alkali-activated cement; concrete structures; tests at high temperatures; cooling down phase; hot strength; residual strength.

\section{Introduction}

For some years, the cement industry invests in the development of new, environment-friendly blended cement products, e.g., supersulfated slag cement (SSC). This cement is mainly made out of blast furnace slag, a by-product of iron making; hence less energy is used during the manufacturing process and less carbon dioxide is produced than in the case of portland cement.

The thermal and mechanical properties of concrete change at elevated temperatures. This change in material properties influences the load-carrying and deformation behavior of concrete structures in case of fire. The rate of increase of temperature across the section in a concrete element is relatively slow, and inner zones are protected against heat. Therefore reinforced concrete structures with adequate structural detailing, e.g., minimum dimensions and cover thicknesses of the reinforcement, usually achieve satisfactory fire resistance without any additional fire protection [1]. However after the fire has been extinguished the heat penetration into the cross section may continue for hours, and is inverted during the cooling phase leading to thermal stresses and cracks [2]. Additionally, chemical reactions, e.g., the reformation of calcium hydroxide during the cooling phase, can widen up micro cracks. A combination of these two phenomena may lead to a significant reduction in the compressive strength of concrete after a fire [3]. Investigations carried out by Felicetti and Gambarova [4] find that the minimum strength is reached after the concrete has cooled down to normal temperature.

For general application of concrete made of supersulfated slag cement, there is a lack of basic knowledge on the mechanical behaviour during and after a fire. A research project on the fire behaviour of concrete made of supersulfated slag cement is currently being carried out at the Institute of Structural Engineering at ETH Zürich. The research project aims at enlarging the theoretical and experimental data on the performance of concrete made of supersulfated slag cement during and after a fire. An extensive testing program using the IBK electric furnace is being conducted to study the tem- perature-dependent loss of strength of concrete and to develop temperature-dependent stress-strain relationships for concrete made of supersulfated and other types of cement for a complete temperature cycle (including cooling phase). The stress-strain relationships can be used as material input parameters for finite-element analysis and for developing calculation models.

\section{Test set up and testing procedure}

The tests were performed using an electric-powered furnace that can reach a temperature of up to $1000{ }^{\circ} \mathrm{C}$. The attainable heating rate at the concrete surface of cylindrical specimens $150 \mathrm{~mm}$ in diameter and $300 \mathrm{~mm}$ in length can be up to $4.5 \mathrm{~K} / \mathrm{min}$. The furnace consists of two U-shaped shells, allowing the test specimen to be placed in the middle of the oven in a metal cage to protect the furnace in case of concrete spalling.

The concrete specimen is loaded with a hydraulic cylinder. At the contact zones a thin layer of gypsum ensures even and centrical force transmission. The test set-up is shown in Fig. 3.

All tests were carried out within a very short time-frame, and the specimens were kept in a controlled climate $\left(20^{\circ} \mathrm{C} / 50 \%\right)$ to reduce the influences of concrete age and moisture content. The tests specimens were heated up slowly to the maximum temperature of $300{ }^{\circ} \mathrm{C}, 500{ }^{\circ} \mathrm{C}$ and $700{ }^{\circ} \mathrm{C}$. After maintaining the temperature level for two hours, the test specimens were cooled down linearly. The compressive strength at maximum temperature (hot strength) was measured, as well as the residual strength during the cooling down phase and after being cooled down to ambient temperature of $20^{\circ} \mathrm{C}$. The general thermal cycle is shown in Fig. 1. The corresponding target temperatures for the hot and residual strength are given in Table 1.

In order to minimize the temperature gradients in the cross section and related thermal stresses, slow heating up and cooling down rates and a conditioning time of 2 hours at maximum temperature were chosen. According to the test results presented in [3] and [4], the heating up rate can be as high as $5 \mathrm{~K} / \mathrm{min}$, while the cooling down rate should not 


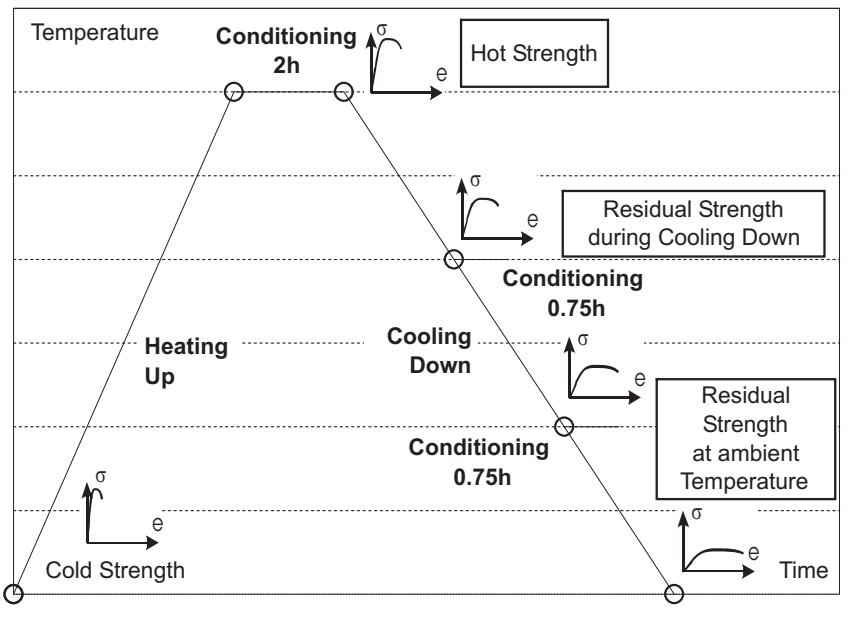

Fig. 1: Full thermal cycle

Table 1: Testing Procedure

\begin{tabular}{|c|c|c|c|c|c|}
\hline $\begin{array}{c}\text { Testing } \\
\text { Series }\end{array}$ & $\begin{array}{c}\text { Max. } \\
\text { Temperature }\end{array}$ & \multicolumn{3}{|c|}{$\begin{array}{c}\text { Tests at target temperature } \\
\text { (hot and residual strength) }\end{array}$} \\
\hline 1 & $300{ }^{\circ} \mathrm{C}$ & $\begin{array}{c}\text { Hot } \\
\text { strength }\end{array}$ & & & $20^{\circ} \mathrm{C}$ \\
\hline 2 & $500{ }^{\circ} \mathrm{C}$ & $\begin{array}{c}\text { Hot } \\
\text { strength }\end{array}$ & $300{ }^{\circ} \mathrm{C}$ & $20^{\circ} \mathrm{C}$ \\
\hline 3 & $700{ }^{\circ} \mathrm{C}$ & $\begin{array}{c}\text { Hot } \\
\text { strength }\end{array}$ & $500{ }^{\circ} \mathrm{C}$ & $300{ }^{\circ} \mathrm{C}$ & $20^{\circ} \mathrm{C}$ \\
\hline
\end{tabular}

exceed $1.0 \mathrm{~K} / \mathrm{min}$. Higher values reduce the formation of calcium hydroxide, causing a higher residual strength which decreases within days after cooling down. A first simple finite element analysis was carried out to predict the maximum heat gradient during heating up and cooling down. In accordance with this first analysis, literature results and a preliminary test, the heating up rate at the surface was chosen as $1.5 \mathrm{~K} / \mathrm{min}$ and the surface cooling down rate as $0.9 \mathrm{~K} / \mathrm{min}$. During the entire heating cycle, the concrete was loaded with a maximum pressure of roughly $0.3 \mathrm{MPa}$, which is less than $0.75 \%$ of the cold strength; hence, the cylinders can be considered as unloaded, since the thermal expansion of the concrete is not affected by any load effects. The free expansion, internal damages caused by cracks and debonding of the cement matrix lead to a lower hot and residual strength compared to the loaded specimens [3] and [4]. A test series with loaded concrete specimens is planned. At the end of the thermal cycle, when reaching the target temperature, the concrete strength was determined inside the furnace. The furnace was not opened; hence the concrete surface temperature remained constant. The load was applied deformation controlled with a constant speed of $0.005 \mathrm{~mm} / \mathrm{s}$. The stress-strain curve was continuously monitored and the test was stopped manually post fracture. The concrete cold strength was determined in an analogous manner with the same deformation speed.

After the testing procedure, the specimens were visually inspected with respect to crack formation and spalling. None of the tested concrete specimens showed loose or missing con- crete parts caused by spalling. Equalizing the contact zones of the specimens with a thin layer of gypsum led to proper results, since the fracture pattern was shaped like a truncated cone.

\section{Test specimens}

The tests were conducted using cylindrical specimens (d $=150 \mathrm{~mm} / L=300 \mathrm{~mm}$ ) made of three different concrete mixtures, a supersulfated slag cement (SSC), a portland-limestone cement (CEM II-A-LL), and an ordinary portland cement (CEM I). The mixing properties of the concrete were identical, apart from the cement used. The cement content was always $300 \mathrm{~kg} / \mathrm{m}^{3}$ with a w/c ratio of 0.55 . Common types of carbonate and siliceous aggregates up to $32 \mathrm{~mm}$ were used to prepare the test specimens. The fresh concrete density was $2420 \mathrm{~kg} / \mathrm{m}^{3}$, decreasing to $2390 \mathrm{~kg} / \mathrm{m}^{3}$ during conditioning in $20{ }^{\circ} \mathrm{C} / 50 \%$ atmosphere.

Before concreting, a petrographic analysis of the aggregates was carried out. The gravel plant is located in the area of an end moraine, hence the main component are based on limestone gravel. The petrographic analysis shows that roughly $57 \%$ of the aggregates consist of carbonate, while $38 \%$ of the gravel components are siliceous.

The specimen diameter used in hot material testing is mostly smaller than $100 \mathrm{~mm}$. These small-scale specimens are insufficient for grading curves with a maximum aggregate size of $32 \mathrm{~mm}$. To ensure adequate compacting of the fresh concrete, cylindrical specimens $150 \mathrm{~mm}$ in diameter and $300 \mathrm{~mm}$ in height were used.

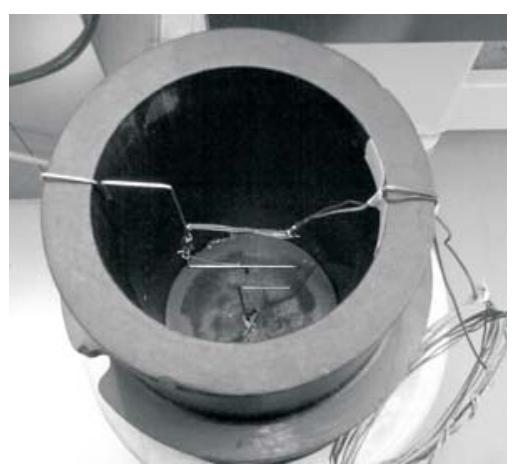

Fig. 2: Thermocouple and formwork

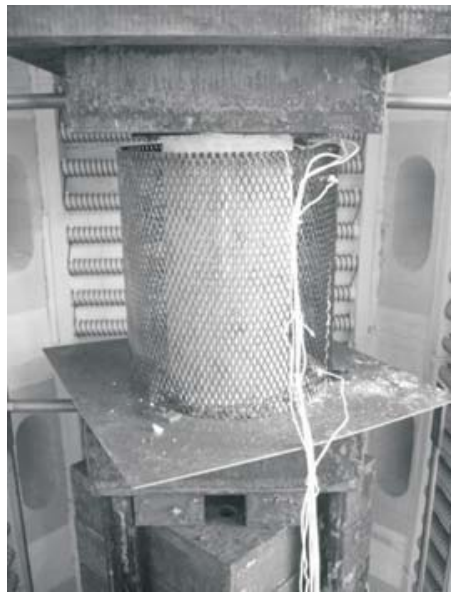

Fig. 3: Concrete specimen in the furnace 


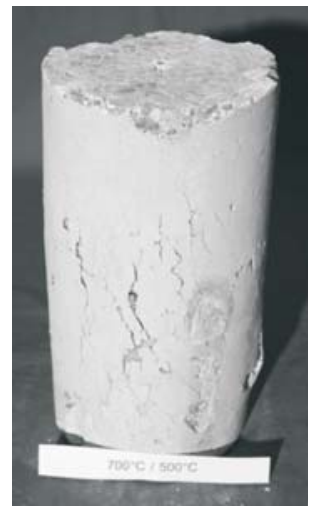

Fig. 4: Concrete specimen after the test

The specimens were produced under laboratory conditions. The facilities were climate-controlled, with a relative humidity of $65 \%$ and a temperature of $20^{\circ} \mathrm{C}$. As formwork, a non-absorbent plastic cylinder was used. Four thermocouples were placed into this formwork before concreting: two in the core, and additionally two at a depth of $30 \mathrm{~mm}$, as shown in Fig. 2. There was a distance of at least $30 \mathrm{~mm}$ between the thermocouples, in order to minimize perturbation due to electric fields. The thermocouples were fixed to a $2 \mathrm{~mm}$ welding wire to ensure that the couples stayed in position during concreting and compacting. This set-up followed generally accepted guidelines [5].

The concrete was poured into the formwork in two stages and was compacted after each stage, using a vibrating table. Striking times and storage conditions for hardened concrete were respected, according to [6]. In accordance with these regulations, the specimens were cured for three days after concreting; they were then placed either in water or in very humid conditions, i.e., temperature of $20^{\circ} \mathrm{C}$ and a relative humidity of at least $95 \%$ up to the age of 28 days from the time of concreting.

According to [7], the specimens have to be conditioned in a dry atmosphere for at least 90 days. The ambient temperature should not exceed $23{ }^{\circ} \mathrm{C}$ and the moisture level should be around $50 \%$ rel. humidity. All cylinders were stored in a $20{ }^{\circ} \mathrm{C} / 50 \%$ conditioning room; the loss of weight of the concrete was monitored on a weekly basis until the specimen was

Table 2. Testing Program tested in the furnace. At the time of testing, the specimens showed no significant loss in weight.

\section{Test program}

Table 2 shows the test program that was carried out. While steps one to four were carried out for all cement types, steps five and six were conducted on a few specimens only. The interim values at step four are determined during the cooling down cycle (see Fig. 1). The first temperature in Table 2 (step 4 - right) indicates the maximum temperature, while the second temperature is the temperature for testing during cooling down.

\section{Test results}

The tested specimens showed no significant difference in strength at room temperature, the average coefficient of variation was less than $5 \%$. The cylindrical cold strength after 90 days was 33.1 MPa for the SSC concrete, 34.3 MPa for the CEM II-A-LL concrete and 40.3 MPa for the CEM I concrete.

During the heating cycle, the temperature at the concrete surface and at the core of the specimen was constantly monitored. It was ensured that the average temperature gradient between surface and core during the heating cycle was never higher than $1 \mathrm{~K} / \mathrm{mm}$.

The measured stress-strain curves for the SSC concrete tests are shown in Fig. 5. The picture on the left includes the cold strength stress-strain curve. The interim values during cooling down are also presented. It can be observed that, at hot stage, the gradient of the curves is monotonic, while at residual stage the gradient shows one inflexion point. This effect increases with increasing maximum temperature and lower cooling temperatures, respectively. This is due to the loss in the bond between the aggregates and the cement matrix during cooling down. The stress strain curves for the CEM II-A-LL and the CEM I cement were similar; the SSC showed higher strains at ultimate load.

Figure 6 shows the reduction factors for hot and residual strength of the specimen with the three different types of cement used. All results are normalized to the corresponding cold strength before testing (cold strength $=1.0$ ). Starting at relative cold strength of 1.0 at $20^{\circ} \mathrm{C}$, the relative hot strength is given by the continuous line, the dots corresponding to the

\begin{tabular}{|c|l|l|}
\hline Step & Measured Category & Temperature Level \\
\hline 1 & Cold Strength & $20{ }^{\circ} \mathrm{C}$ \\
\hline 2 & Hot strength & $300{ }^{\circ} \mathrm{C} ; 500{ }^{\circ} \mathrm{C} ; 700{ }^{\circ} \mathrm{C}$ \\
\hline 3 & Residual Strength & $\begin{array}{l}\text { After concrete cooled down to } 20{ }^{\circ} \mathrm{C} \text { from the three } \\
\text { hot strength temperature levels from step } 2\end{array}$ \\
\hline 4 & Interim Values & $700{ }^{\circ} \mathrm{C}-500{ }^{\circ} \mathrm{C} ; 700{ }^{\circ} \mathrm{C}-300{ }^{\circ} \mathrm{C} ; 500{ }^{\circ} \mathrm{C}-300{ }^{\circ} \mathrm{C}$ \\
\hline 5 & $\begin{array}{l}\text { Slow heating rate } \\
\text { (on CEM II-A-LL cement only) }\end{array}$ & $\begin{array}{l}500{ }^{\circ} \mathrm{C}-\text { hot strength } \\
500{ }^{\circ} \mathrm{C}-20{ }^{\circ} \mathrm{C} \text { (residual strength after cooling down) }\end{array}$ \\
\hline 6 & $\begin{array}{l}\text { Magnetic Resonance Imaging } \\
\text { (one CEM I specimen only) }\end{array}$ & $300{ }^{\circ} \mathrm{C}-20{ }^{\circ} \mathrm{C}$ \\
\hline
\end{tabular}




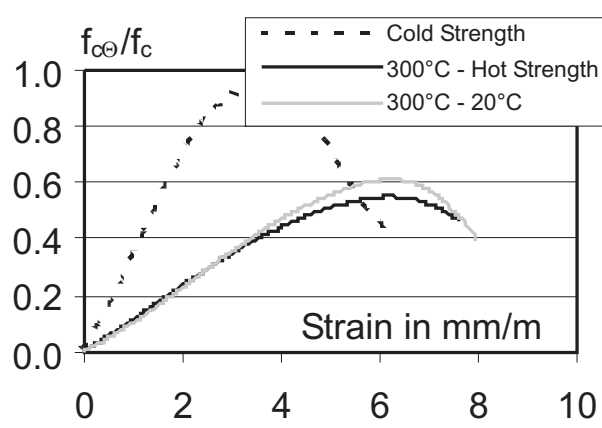

(a)

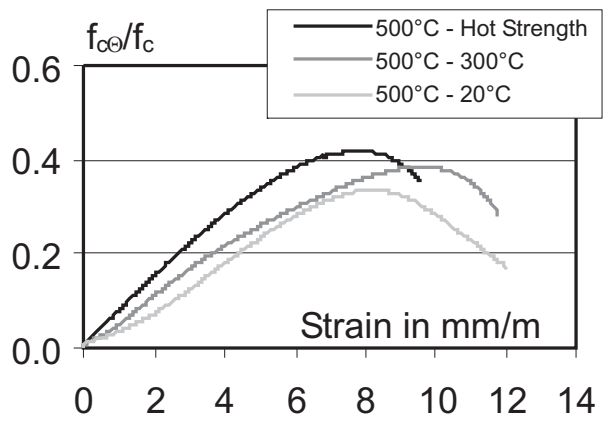

(b)

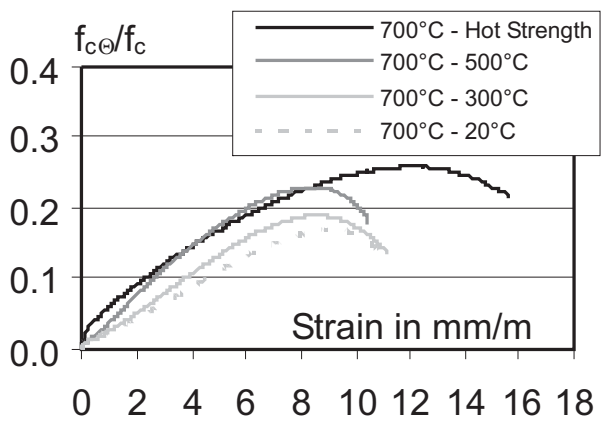

(c)

Fig. 5: Stress-Strain relation for SSC concrete for different heating up levels: (a) max. temp. level of $300{ }^{\circ} \mathrm{C}$ (including cold strength), (b) max. temp. level of $500{ }^{\circ} \mathrm{C}$, (c) max. temp. level of $700^{\circ} \mathrm{C}$ test results at temperature levels of $300{ }^{\circ} \mathrm{C}, 500{ }^{\circ} \mathrm{C}$ or $700{ }^{\circ} \mathrm{C}$. After reaching the maximum temperature level, the loss in strength during and after cooling down is found by following the dotted line to the left until reaching the residual strength at ambient temperature of $20^{\circ} \mathrm{C}$ after a full thermal cycle.

As shown in Fig. 6, the specimens with SSC show slightly lower hot strength in comparison to CEM II-A-LL and CEM I cement at the $300{ }^{\circ} \mathrm{C}$ and $500{ }^{\circ} \mathrm{C}$ temperature level. At higher temperature levels, i.e. $700^{\circ} \mathrm{C}$, all cements show similar performances. While the loss in strength during cooling down for SSC was nearly linear, CEM I and II show a non-linear residual strength development, with increased losses in strength while cooling down from $300{ }^{\circ} \mathrm{C}$ to $20^{\circ} \mathrm{C}$.

In general, the losses in strength from hot to residual stage at ambient temperature increase with increasing maximum temperature levels. The concrete specimens cooled down from a maximum temperature of $300{ }^{\circ} \mathrm{C}$ had an average residual strength of $91 \%$ of the hot strength. At $500{ }^{\circ} \mathrm{C}$ the average residual strength was $72 \%$, and after cooling down from $700{ }^{\circ} \mathrm{C}$ the average residual strength was $69 \%$.

\section{Magnetic resonance imaging}

Using magnetic resonance imaging, the entire concrete cylinder was scanned slice by slice. Higher densities of any scanned objects inside the concrete cylinder, e.g., aggregates,

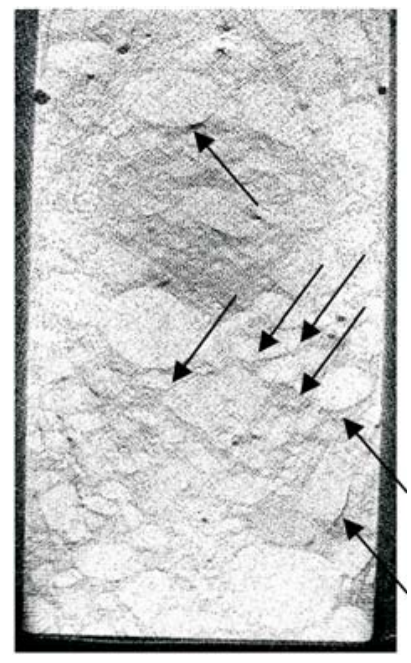

Fig.7. Magnetic resonance imaging

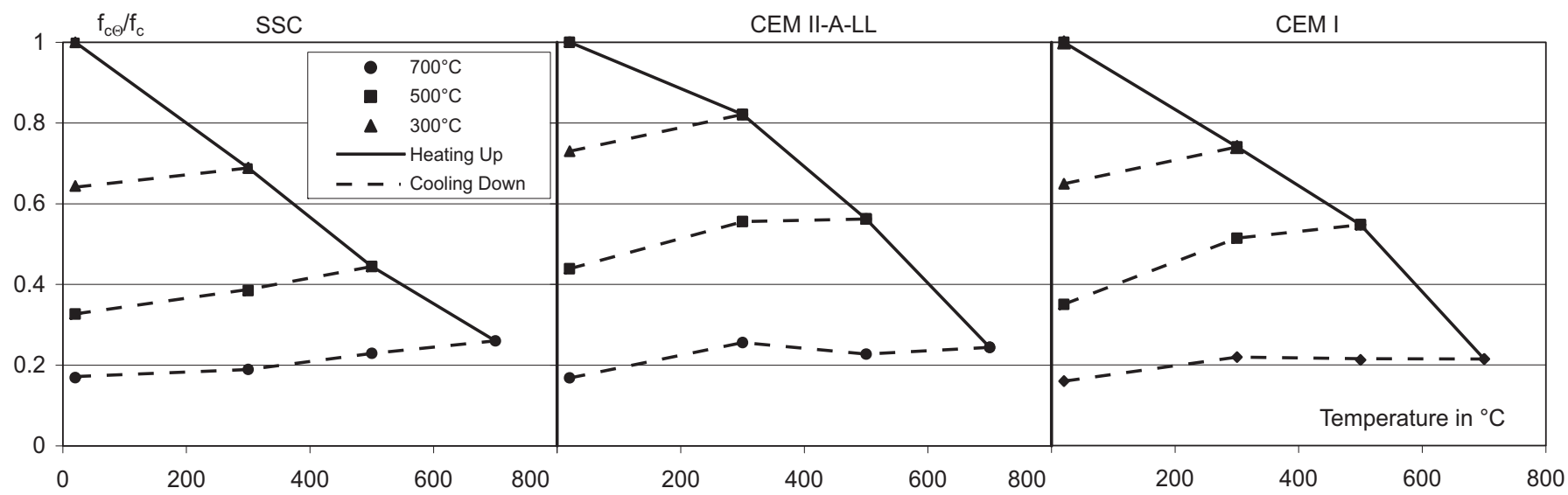

Fig. 6: Temperature-Strength relation for three different cements during heating up and cooling down phase 
are shown in brighter greyscales. Hence, cracks, voids and air pores are shown as black lines or dots in the image.

After heating one CEM I specimen up to $300{ }^{\circ} \mathrm{C}$, it was cooled down and inspected by magnetic resonance imaging. The main aim was to study the crack formation inside the specimen, and to investigate if any loss in bond between the cement matrix and the aggregates had occurred. Scans on SSC and CEM II-A-LL samples are planned.

Fig. 7 shows that the bond between the aggregates and the cement matrix became loose over the entire cross section. The arrows indicate the zones where the bond was affected.

\section{Conclusions}

The results of this first testing series on the hot and residual strength of concrete after a fire, including cooling, can be summarized as follows:

- The difference in strength in hot and residual stage after cooling down to ambient temperature is significant. The losses in residual strength during cooling down increase with higher temperatures.

- During the cooling down phase, a non-linear material behaviour for CEM I and CEM II is observed.

- Even after cooling down from a moderate temperature of $300{ }^{\circ} \mathrm{C}$, debonding effects between the cement matrix and the aggregates could be observed by magnetic resonance imaging.

- Supersulfated slag cement (SSC) performs not much different than ordinary portland cement.

\section{Aknowledgements}

Thanks to Holcim Group Support Ltd. for supplying the test specimen.

\section{References}

[1] EN 1992-1-2:2004; Eurocode 2: Design of concrete structures; Part 1-2: General rules - Structural fire design.

[2] Frangi, A., Tesar, C., Fontana, M.: Tragwiderstand von Betonbauteilen nach dem Brand. Bauphysik, Vol. 28 (2006), p. 170-183.

[3] Hertz, K. D.: Concrete Strength for Fire Safety Design. Magazine of Concrete Research, Vol. 57 (2005), p. 445-453.

[4] Fire Design of Concrete Structures - Structural Behaviour and Assessment. CEB-FIP state-of-art report bulletin Vol. 46 (2008).

[5] ABM-Paper 2A by the German Federal Institute for Materials Research and Testing, 1990

[6] EN 12390-2:2008; Testing hardened concrete - Part 2: Making and curing specimens for strength tests.

[7] EN 1363-1:1999; Fire resistance tests - Part 1: General requirements.

Eike Wolfram Klingsch

e-mail: klingsch@ibk.baug.ethz.ch

Andrea Frangi

Mario Fontana

Institute of Structural Engineering, Steel, Timber and Composite Structures

ETH Zürich, Switzerland 